\title{
Comparison of the earth's crust geothermal field in Northern Tien Shan region with seismic characteristics
}

\author{
Andrey Vilayev ${ }^{1,}$, Zhumabek Zhantaev ${ }^{1}$ \\ ${ }^{1}$ National Center of Space Research and Technology, Institute of Ionosphere, 050020 Kamenskoe \\ Plateau, Almaty, Kazakhstan
}

\begin{abstract}
The deep crustal temperatures of the Northern Tien Shan region are being calculated on the basis of direct measurements of the heat flow and empirical relation of geothermal parameters and seismic velocities. For this purpose the applied method of numerical solution of conductive heat transfer equation takes into account additional sources of heat release due to radioactive decay. Thermoelastic deformations, reaching $20-40 \%$ of the total lithostatic pressure at depths of $35-60 \mathrm{~km}$, are determined. The criteria controlling the distribution of hypocenters of earthquakes have been determined in accordance with the morphology of the regions of excess temperatures and thermal stresses.
\end{abstract}

\section{Introduction}

The temperature field largely determines the physical state of the Earth's lithosphere material. The study of the thermal state of the earth's interior is especially important for areas where intensive tectonic movements occur, accompanied by strong and catastrophic earthquakes. Northern Tien Shan is one of such areas. This is evidenced by the earthquakes occurred in the region: Vernenskoye $(\mathrm{Ms}=7.1,1887)$, Chilik $(\mathrm{Ms}=8.1,1889)$, Kemin (Ms $=8.0,1911)$, Zhalanash $(\mathrm{Ms}=6.8,1978)$, Bisorun $(\mathrm{Ms}=5.9,1990)$, etc. The aim of this paper is to examine the distribution of the deep thermal field of the Earth's crust of Northern Tien Shan to assess the seismic activity of the region.

\section{Methods and Materials}

The method used for the research implied numerical modelling of the Earth's crust temperatures based on the results of heat transfer equations with the use of experimental thermophysical parameters - heat flow, thermal conductivity coefficient, radiogenic heat generation. A comparative analysis of the parameters of the calculated geothermal model with the distribution of earthquakes of the territory has been performed.

\footnotetext{
*Corresponding author: vilayev@gmail.com
} 
Mathematical model. The basic equation of stationary conductive heat transfer for longterm geological processes in a heterogeneous anisotropic elastic medium can be expressed as [1]:

$$
\nabla k \nabla T+k \nabla^{2} T+A(x, y, z)=0
$$

where $\mathrm{k}$ is the thermal conductivity of the rocks at the point with coordinates $(\mathrm{x}, \mathrm{y}, \mathrm{z}), \mathrm{T}$ is the temperature, and $\mathrm{A}(\mathrm{x}, \mathrm{y}, \mathrm{z})$ is the radioactive generation of heat in a unit volume. The symbol $\nabla$ denotes the differential Laplace operator in three-dimensional space

$$
\nabla=\left(\frac{\partial^{2}}{\partial x^{2}}+\frac{\partial^{2}}{\partial y^{2}}+\frac{\partial^{2}}{\partial z^{2}}\right) T
$$

The coefficient of thermal conductivity at the point (x,y, z), taking into account the temperature dependence, was calculated for the Northern Tien Shan region as follows:

$$
k=0.01157 V p^{3} *\left(-0.9+0.00246 T+343 T^{-1}\right)^{-1}
$$

where $\mathrm{Vp}$ - velocity of seismic waves $(\mathrm{km} / \mathrm{s}), \mathrm{T}$ - initial temperature in ${ }^{\circ} \mathrm{K}$.

Radiogenic heat release in the Earth's crust due to the decay of radioactive elements ${ }^{40} \mathrm{~K}$, ${ }^{238} \mathrm{U}$ and ${ }^{232} \mathrm{Th}$ was calculated from the empirical relationship between the heat generation $\mathrm{A}\left(\mu \mathrm{W} / \mathrm{m}^{3}\right)$ and the velocity $\mathrm{Vp}(\mathrm{km} / \mathrm{s})$ for the earth crust of the Northern Tien Shan:

$$
A=0.3125^{* *}\left(10^{-5}\right) \cdot \exp \left(1.61^{*} \mathrm{Vp}\right)
$$

Equation (1), with allowance for $(3,4)$, is solved using the numerical method of finite differences on the grid $41 \times 31 \times 20$ in the variable direction scheme [2].

The heat flow determined from well measurements was taken as a boundary condition for heat transfer on the surface; according to meteorological data, the average annual temperature of the earth's surface is $10{ }^{\circ} \mathrm{C}$ at a depth of $1 \mathrm{~m}$. The initial temperature distribution corresponded to a linear geothermal gradient. The lateral boundary conditions the heat flow to zero through the vertical boundaries of the model. At the lower boundary of the modelling region, the mantle component of the heat flow was determined as the difference between the flow on the surface and the radiogenic component from the decay of the $\mathrm{U}, \mathrm{Th}, \mathrm{K}$-containing rocks, as well as constant temperature, assuming the presence of the rock at the depth of $120 \mathrm{~km}$ with Solidus temperature $\left(1370{ }^{\circ} \mathrm{C}\right)$.

To calculate the effective thermal stresses in the earth's crust, the working formula is applied [3]

$$
\tau_{z z}=\rho g z+3 \beta K\left(T-T_{0}\right)
$$

where $-3 \beta$ is the volume coefficient of thermal expansion of the rocks, $\mathrm{K}$ is the bulk modulus, $\rho$ is the density, $g$ is acceleration of gravity, and $\left(\mathrm{T}-\mathrm{T}_{0}\right)$ is the temperature deviation from the initial linear distribution. The product $3 \beta \mathrm{K}\left(\mathrm{T}-\mathrm{T}_{0}\right)$ denotes thermal stresses caused by a combination of a nonlinear temperature change. The bulk modulus $\mathrm{K}$ is calculated from the ratio of the $\mathrm{P}$-waves and $\mathrm{S}$-waves velocities in the conditions of natural bedding of the rocks:

$$
K=\rho\left(V_{p}^{2}-4 / 3 V_{s}^{2}\right)
$$

where $\mathrm{Vp} / \mathrm{Vs}=2.04$ stands for the rocks of the Northern Tien-Shan, Density of rocks is defined in each node of the grid model according to the law of linear approximation: 


$$
\rho=\left(0.315 V_{p}+0.74\right) * 10^{3}
$$

Taking into account the sphericity of the surface and the considerable spatial dimensions of the model, equation (1) was solved in spherical coordinates relative to the center of the Earth:

$$
\nabla T=\frac{1}{r^{2}} \frac{\partial}{\partial r}\left(r^{2} \frac{\partial T}{\partial r}\right)+\frac{1}{r^{2} \sin \theta} \frac{\partial}{\partial \theta}\left(\sin \theta \frac{\partial T}{\partial \theta}\right)+\frac{1}{r^{2} \sin ^{2} \theta} \frac{\partial^{2} T}{\partial \varphi^{2}}
$$

\section{Results and Discussion}

Thermophysical model. Geologically, the region is a part of the Alpine neotectonic belt and includes the longitudinally extending mountain ranges Kungei and Zailiyskiy Ala-Tau separated by intermontane depressions [4]. From the east, the region is bordered by spurs of the Dzhungar Ala-Tau mountain ranges, and from the west by the eastern end of the Chu-Ili Mountains. In the earth's crust, according to geophysical data, sedimentary, granite (upper and lower), and basalt layers are distinguished. The thickness of the earth's crust varies from $42 \mathrm{~km}$ to $55-60 \mathrm{~km}$, increasing southeastward towards the mountain structures of the Tien Shan and Dzungaria.

Structure of seismic velocities field. The initial experimental base of the deep structure of the earth's crust was P-waves velocities data to the depth of $100 \mathrm{~km}$ within the region with

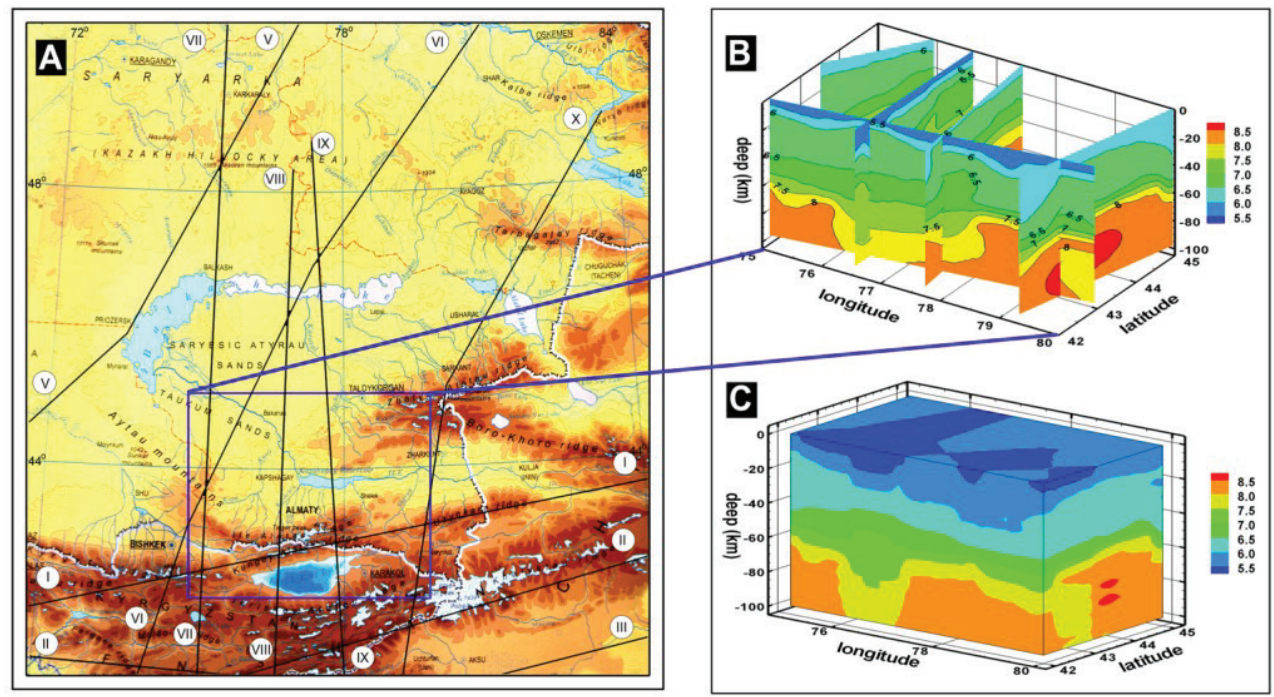

coordinates determined by the methods of the DSS, the DSS-MOVZ [4,5]. (Fig. 1).

Fig. 1. Geotraverse system of P-waves velocity lithospheric modelling: A - planned position of geotraverses, B - 2D models P-waves velocity by profiles, C - 3D velocity model in study area

Thermal conductivity. The average values of thermal conductivity coefficient of the sedimentary layer are determined in the range $1.5 \div 1.7 \mathrm{~W} / \mathrm{m} \cdot \mathrm{K}$, granite - about 2.6, dioritic $2.2 \div 2.3 \mathrm{~W} / \mathrm{m} \cdot \mathrm{K}$, basaltic $-3 \div 3.1 \mathrm{~W} / \mathrm{m} \cdot \mathrm{K}$. For the upper mantle, the thermal conductivity coefficient corresponds to $3.2 \mathrm{~W} / \mathrm{m} \cdot \mathrm{K}$. 
Radiogenic heat generation. A comparison analysis of the estimates of the heat generation values of different layers of the earth's crust according to the data of [6-8] and equation (4) showed satisfactory convergence. Magmatic formations developed in the North Tien Shan and Dzungar blocks are characterized by a higher level of heat generation. The highest concentration of radioactive elements is observed in the upper part of the granite layer at the depths $5-30 \mathrm{~km}$. The heat release of the granite layer is from 1.0 to $2.0 \mu \mathrm{W} / \mathrm{m}^{3}$, sedimentary layer - from $0.2 \mu \mathrm{W} / \mathrm{m}^{3}$ to $1.0 \mu \mathrm{W} / \mathrm{m}^{3}$. With depth, the radioactive heat release decreases unevenly. The lower part of the granite layer of the mountain areas is characterized by an intensity of $0.6 \div 1.1 \mu \mathrm{W} / \mathrm{m}^{3}$, the platform part is $0.5 \div 1.0 \mu \mathrm{W} / \mathrm{m}^{3}$. The heat generation of the basalt layer is $0.5 \mu \mathrm{W} / \mathrm{m}^{3}$.

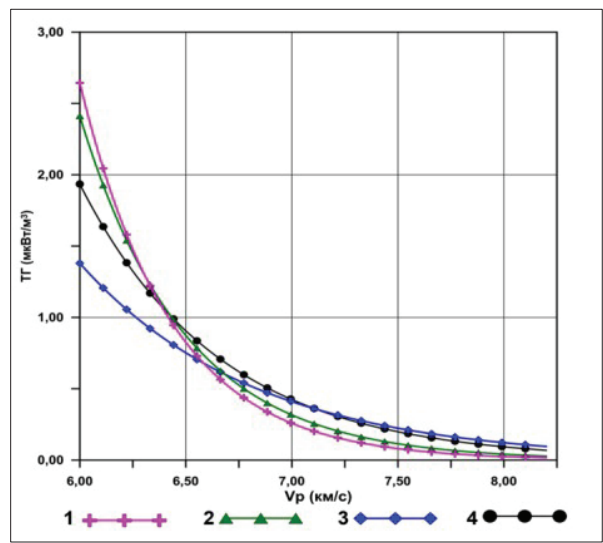

Fig. 2. Dependence of the heat release rate intensity in the crust rocks from elastic waves velocity: 1 $-[6], 2-[7], 3-[8], 4-$ equation (4).

Heat flow. The surface heat flow (HF) map is compiled from the data of $[9,10]$. In addition, 249 well measurements performed by the authors were taken into account. The average density of the points of heat flow determination is 1 measurement per $18 \mathrm{~km}^{2}$

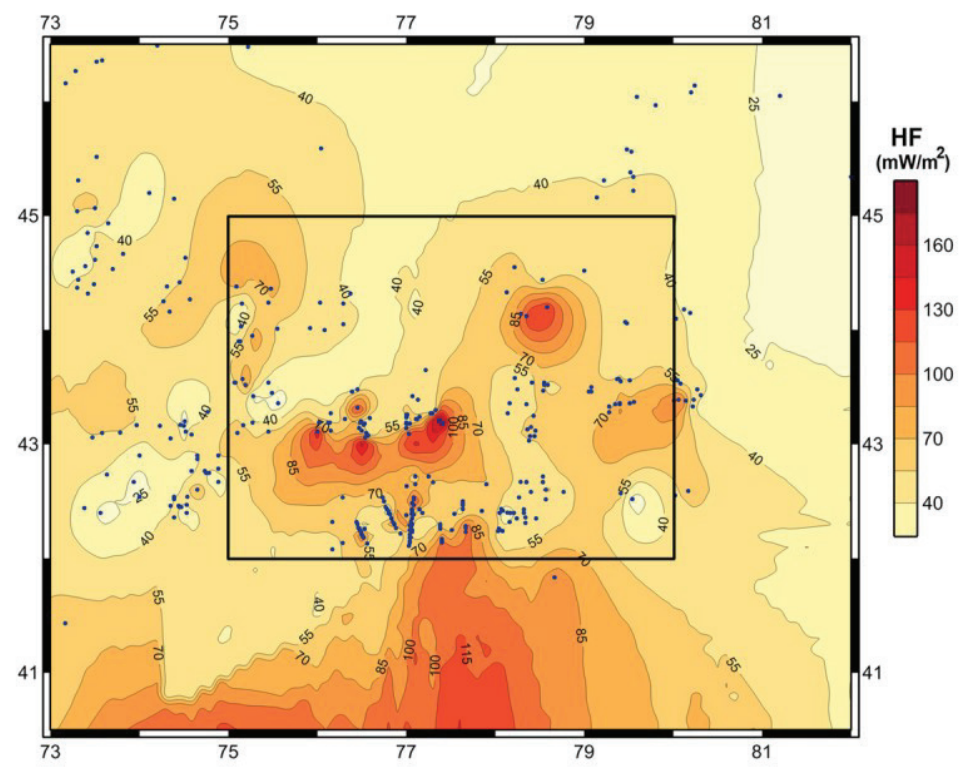

Fig. 3. The heat flow in the northern Tien Shan region $\left(\mathrm{mW} / \mathrm{m}^{2}\right)$ : o - points of measurements in the wells, black outline - area modeling. 
Distribution of the HF in the region corresponds to the data for the areas of Cenozoic tectonic activity. Three areas with different heat flow regime can be distinguished: - highaltitude areas, platform part and modern intermontane depressions. High-altitude areas are characterized by an increased level of heat flow from $54 \mathrm{~mW} / \mathrm{m}^{2}$ to $266 \mathrm{~mW} / \mathrm{m}^{2}$ with an average value of $63 \mathrm{~mW} / \mathrm{m}^{2}$. The heat flow density in intermountain depressions varies from $31 \mathrm{~mW} / \mathrm{m}^{2}$ to $119 \mathrm{~mW} / \mathrm{m}^{2}$ with an average value of $54 \mathrm{~mW} / \mathrm{m}^{2}$. The heat flow of the platform part of the area is $40 \div 45 \mathrm{~mW} / \mathrm{m}^{2}$. The contribution of the radiogenic component of the heat flow to the total HF is from $60 \%$ to $90 \%$.

Geothermal model. The distribution of heat flow, the coefficient of thermal conductivity of rocks and radiogenic heat generation were used to calculate the field of deep crustal temperatures of the Northern Tien Shan (Fig. 4). The structure of the thermal field was studied by dividing the calculated temperatures into a stationary (linear) and anomalous. The anomalous (excess) temperatures are determined by subtracting the stationary component corresponding to a linear geothermal gradient of $12{ }^{\circ} \mathrm{C} / \mathrm{km}$ from the calculated field.

There is a linear decrease in temperatures from the south to the north from the mountain structures to the platform part of the area. The horizontal temperature gradients decrease from $1.5{ }^{\circ} \mathrm{C} / \mathrm{km}$ for mountain ranges to $0.5{ }^{\circ} \mathrm{C} / \mathrm{km}$ in this direction. The absolute temperature is $600-800{ }^{\circ} \mathrm{C}$ at the depth of $40 \mathrm{~km}, 850-1050{ }^{\circ} \mathrm{C}$ at the depth of $80 \mathrm{~km}$ and $1200{ }^{\circ} \mathrm{C}$ at the depth of $100 \mathrm{~km}$. In the depth interval from $20 \mathrm{~km}$ to $45 \mathrm{~km}$, a temperature anomaly with increased values of excess temperatures up to $250{ }^{\circ} \mathrm{C}$ relative to the linear distribution was determined. The anomaly of excess temperatures is elongated in the sub latitudinal direction just above the boundary of $\mathrm{M}$.
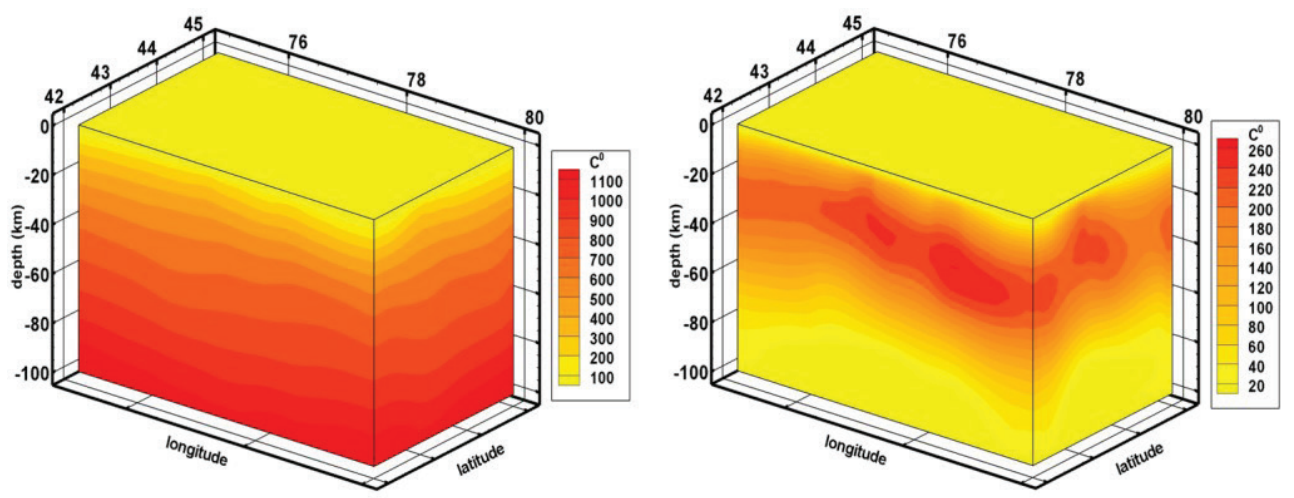

Fig. 4. Results of temperature distribution modelling in the Earth's crust of the Northern Tien Shan region. Left - integrated temperature field $\left({ }^{\circ} \mathrm{C}\right)$, right - anomalous (excess) temperatures $\left({ }^{\circ} \mathrm{C}\right)$.

Thermoelastic stresses. The operating pressure is calculated as the sum of the lithostatic pressure resulting from the mass of overlying rocks and thermoelastic stresses due to uneven heating and inhomogeneity of physical-mechanical properties (equation 5).

At depths of $30 \div 50 \mathrm{~km}$, the contribution of temperature stresses is $12 \% \div 27 \%$ of the lithostatic pressure and reaches $0.45 \mathrm{GPa}$ (Fig. 5). The ratio of the total pressure (with allowance for thermobaric) and lithostatic pressure in the region of anomalous temperatures is $1.3 \div 1.4$. The calculations are in the range of the experimental data of mineral equilibrium, showing that the tectonic pressure can reach up to $100 \%$ of the lithostatic and the values of the first gigopascals [11]. 

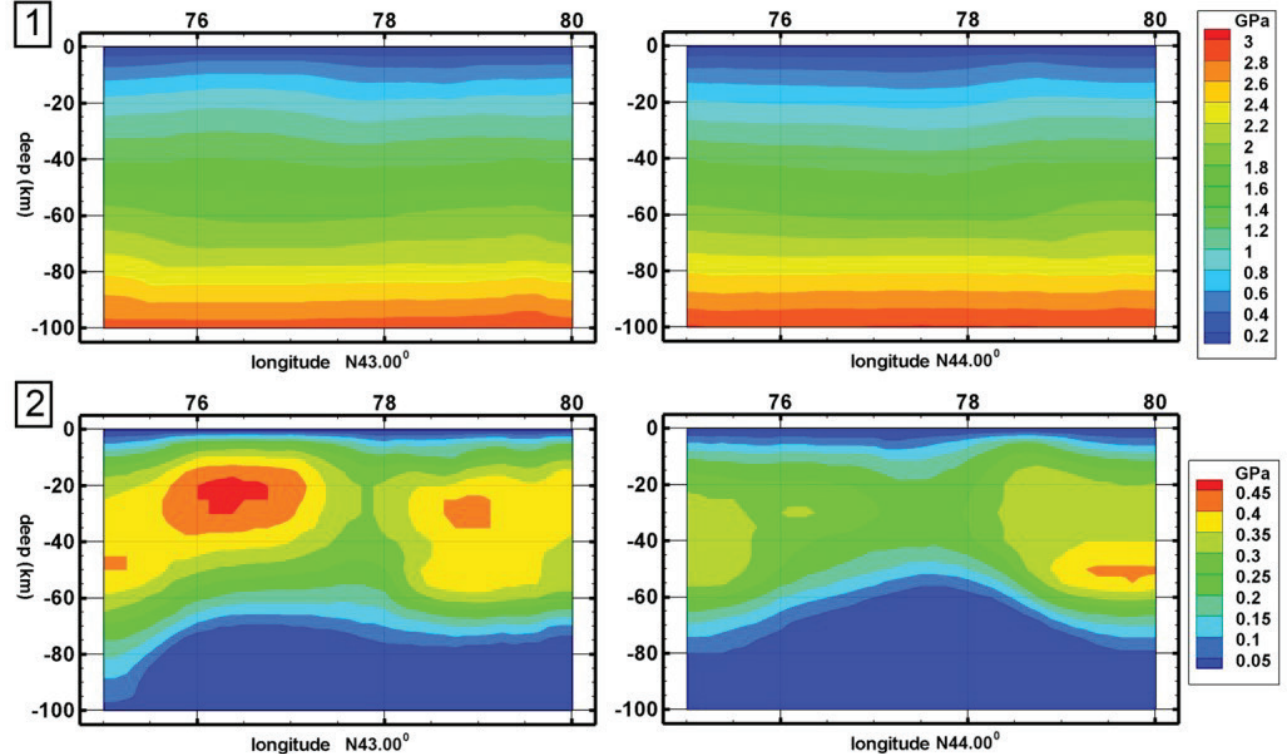

Fig. 5. Depth distribution of thermal stresses in the latitude of $N 43^{0}$ и $N 44^{0}: 1$ - total lithostatic pressure and thermal stress, 2 - thermal stresses.

Comparison of geothermal constructions with seismic regime. The seismogenic zone of the Northern Tien Shan is characterized by a seismoactive layer up to $35 \mathrm{~km}$ thick. The lower part of the crust practically does not contain foci of earthquakes. The isotherm morphology of excess temperatures of $230{ }^{\circ} \mathrm{C}$ in the area of anomalous heating and the isobaric surface of thermoelastic stresses of $0.35 \mathrm{GPa}$ can be attributed to the criteria that controls the distribution of earthquake hypocenters in the earth's crust (Fig. 6).
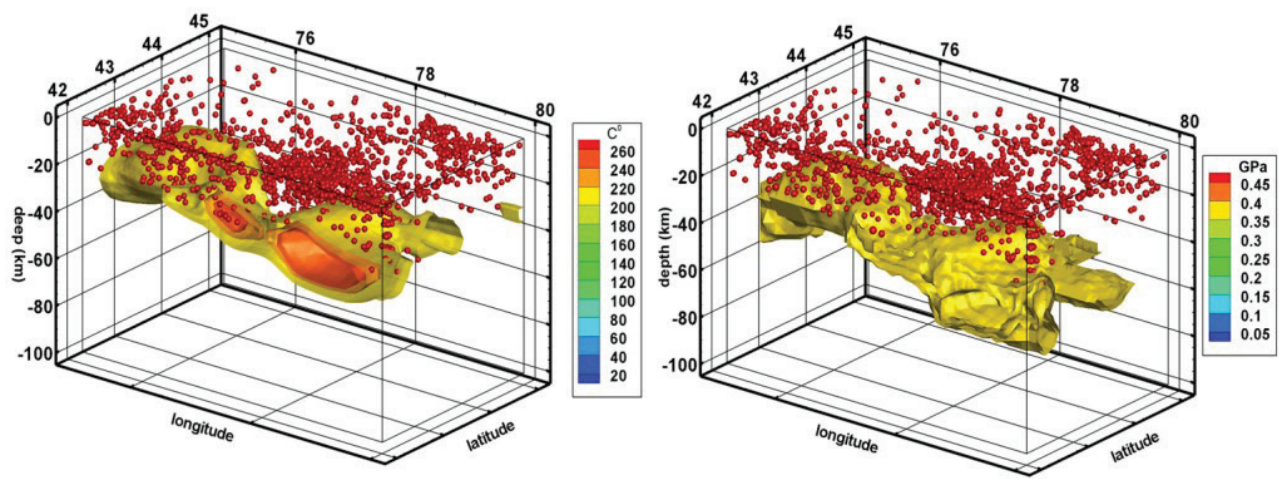

Fig. 6. Isothermal surface of anomalous temperatures of $230{ }^{\circ} \mathrm{C}$ (left) and isobaric surface of thermoelastic stresses of $0.35 \mathrm{GPa}$ (right) that control the earthquakes' hypocenters distribution in the earth's crust of Northern Tien Shan.

A comparison of the heat flow distribution and earthquakes of the average energy class (9.0-10.5) distribution on the plan shows that the epicenters are concentrated mainly in the regions of low HF values (Fig. 7). The increased density of epicenters here can be explained by the lower viscosity properties of the earth's crust and increased fragility of the 
rocks. We can assume a fragile mechanism of the earthquakes formation by reducing the plasticity limit of the material of the crust. The question requires further study.

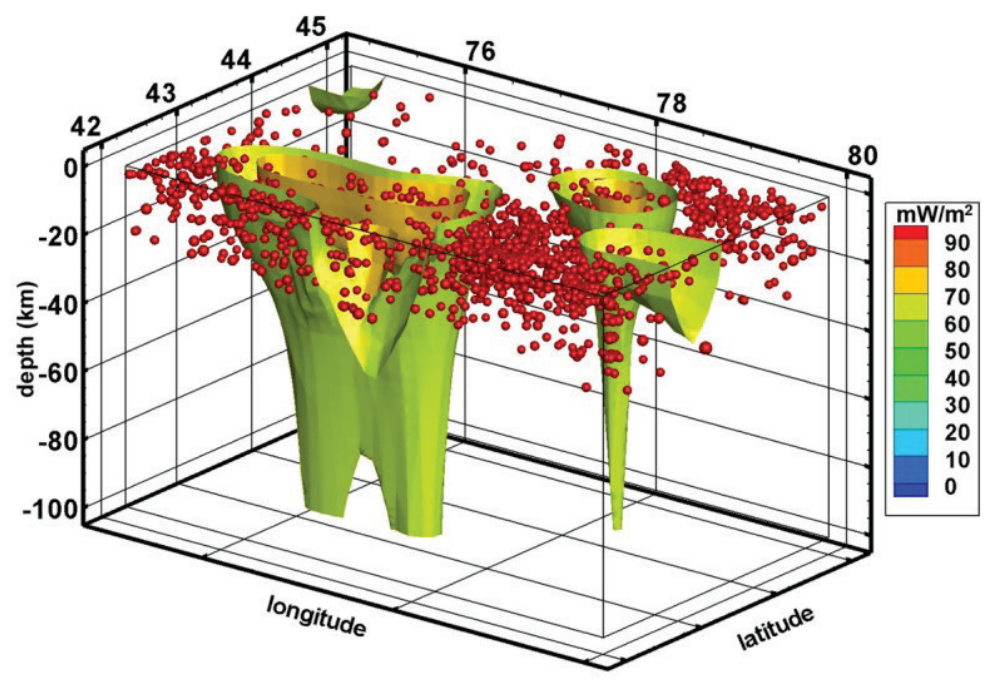

Fig. 7. Model of the heat flow of the Northern Tien Shan with hypocenters of earthquakes

However, the catastrophic earthquakes of the last century (Vernenskoye, Ms = 7.1, 1887; Chilik, Ms = 8.1, 1889; Keminskoye, Ms $=8.0,1911$ ) occurred in the areas of increased heat flow values. We assume that in these regions the phase transformations of eclogitebasalt under the influence of high-temperature fluids (more than $650{ }^{\circ} \mathrm{C}$ ) could take place. These temperatures are reached at depths of $35-60 \mathrm{~km}$. In the melting regions, the volume of rocks increases and their density decreases, and as a result, vertical movements within the crust are activated above the melting zone. The mountains are growing up due to the increase in the volume and the growth of the mountains "roots" down through the melting of basalts. Thus conditions for catastrophic earthquakes are being formed.

\section{Conclusion}

Geothermal modelling allows us to conclude that temperature regime has the prevailing influence on the development of the seismic processes in continental conditions. One of the crucial aspects is determining the high-temperature regions with excess temperatures of $100-250{ }^{\circ} \mathrm{C}$ above the solidus, which can lead to partial melting of rocks.

The accumulation of thermoelastic stresses in the earth's crust can be considered as one of the criteria of seismic activity observed in the Northern Tien Shan region. The distribution of the average energy class earthquakes hypocenters is controlled by the region of excess temperatures up to $230^{\circ} \mathrm{C}$ and the isobar of thermal stresses less than $0.35 \mathrm{GPa}$.

The combination of numerical simulation of the earth's crust temperature regime in the Northern Tien Shan region and seismic data provides additional information for predictive results on the possible mechanisms and physical parameters of the seismoactive environment of the region.

\section{References}

[1] P. Vincenzo, V. Massimo, Ch.Paolo Geothermics. Heat Flow in the Lithosphere, (2014)

[2] A. Samarskii, A. Gulin Chislennye metody (1989) (rus) 
[3] J. Jaeger, N. Cook, and R. Zimmerman Fundamentals of rock mechanics (2007)

[4] A. Timush Seismotektonika lithosphery Kazakhstana (2011) (rus)

[5] Seismicheskoe rayonirovanie Respubliki Kazakhstan (2000) (rus)

[6] L. Rybach, G. Bantebarth Relationships between the petrophysical properties, density, seismic velocity, heat generation and mineral logical constitution, Earth and Planet Sc. letters, 57, 367-376 (1982)

[7] A. Smyslov, U. Moiseenko, T. Chadovich Teplovoy rezhym i radioaktivnost Zemli (1979) (rus)

[8] V. Gordienko, O. Zavgorodniaia, N. Iakobi Teplovoy potok kontinentov (1982) (rus)

[9] J. Davies Global map of solid Earth surface heat flow, Geochemistry, Geophysics, Geosystems, doi:10.1002/ggge.20271 (2013)

[10] W. Gosnold, B. Panda The Global Heat Flow Database of The International Heat Flow Commission, http://www.und.edu/org/ihfc/index2.html (2011)

[11] J. Pleuger and Y. Podladchikov A purely structural restoration of the NFP20-East cross section and potential tectonic overpressure in the Adula nappe (central Alps), Tectonics, 33, 656-685 (2014) 